\title{
CHALLENGES AND ADVANTAGES OF DISTANCE LEARNING SYSTEMS
}

\section{Greta KEREMIDCHIEVA and Plamen YANKOV}

$\mathrm{D}$ istance learning has been around for ages. From the moment you decide you would like to continue your education, the Internet can provide access to detailed information about the many institutions and distance-learning courses currently available to you worldwide - information about the teachers, deadlines, grants and fees. A course web site might include a syllabus, a summary of lessons, notes, links to helpful sites and related research, projects done by students, model assignments and a long list of etceteras considered impractical under the more traditional system. The interactivity of the Web allows for spontaneous feedback and rapid change, without the hassle of endless photocopying.

During the course of studies, many different applications of the Internet may be used. For example, distance-learning courses now customarily take advantage of the speed of basic e-mail to forward reading lists, assignments and course support materials. Communication with the course instructor is more efficient this way and questions can be handled more swiftly. According to evaluations from the fall of 1996 at the University of Illinois, the students reported increased their communication with professors 64 percent and the quality of interaction with instructors 57 percent. At the same time the faculty reported increased communication with students 92 percent and the quality of interaction with students 88 percent.

Contact between classmates becomes feasible, making group tasks and project work real options for the isolated distance learner. It should also be much easier to stay in contact and keep abreast of developments after the course ends. Post-course support and follow-up can take place via discussion boards or mailing lists at your convenience. The survey mentioned above proved that communication between students increased 43 percent, whereas students commented "I learned much more than I ever had due to the high interaction between student-student and studentteacher." 
As Eastmond defines the philosophy of distant learning, it "breaks down barriers for adult learners and shifts emphasis from how or where learning takes place to learner outcomes". A further comparison between traditional and distributed learning will mark differences in various aspects. While in the traditional process teachers lecture and students listen, in the process of distributed learning teachers guide and students are active. Individual work has been replaced by teamwork. Fact-centered learning of specialized subjects has changed into problem-centered integrated studying. Furthermore, in the old classroom teachers were the primary resource of materials and knowledge, while the new method makes multiple resources available to the student. Regarding the teaching materials, what used to be predominantly print media became a mixture of media.

All teachers, from the most traditional to the most innovative, can find uses for the distance learning method in their teaching. There is plenty of opportunity for short, quick practice activities as well as full-blown tasks and extensive projects. Though the distance learning method of teaching will not substitute for a good teacher completely, it will immensely enrich the classroom resources and can be used whatever the teacher's approach to language teaching.

Two factors are essential to computer-mediated learning success, both for faculty and students. First, this is prior computer and networking background, and second, the existence of a support person or team. Despite the ease of point-and-click technology, teachers should plan to spend sufficient time using the technology for themselves both as a resource for materials and a teacher development tool - before trying to use it with students. Most of the students are experienced users of the Internet. On the other hand, certain students face computers with intense anxiety, sometimes to the point of technophobia. This does not make using the technology unworkable, but requires very skillful handling.

Connected to the problems in realization of projects for distance education it is important for their software designers to apply some of the proven in action current approaches for constructing network software management system of distributed system and application software, designed to support the process of distance education and existing strategies for controlling dynamical data exchange in the world wide computer networks.

Agent/ Manager Paradigm - Most of modern network software management solutions are based on the agent/manager paradigm, in which management communication occurs between a manager and an agent system, as illustrated in Figure 1.

Practically in many cases specific management system may function as a manager for some applications and as an agent for other applications. The agent/manager paradigm is similar to the client/server paradigm except for some minor differences. 


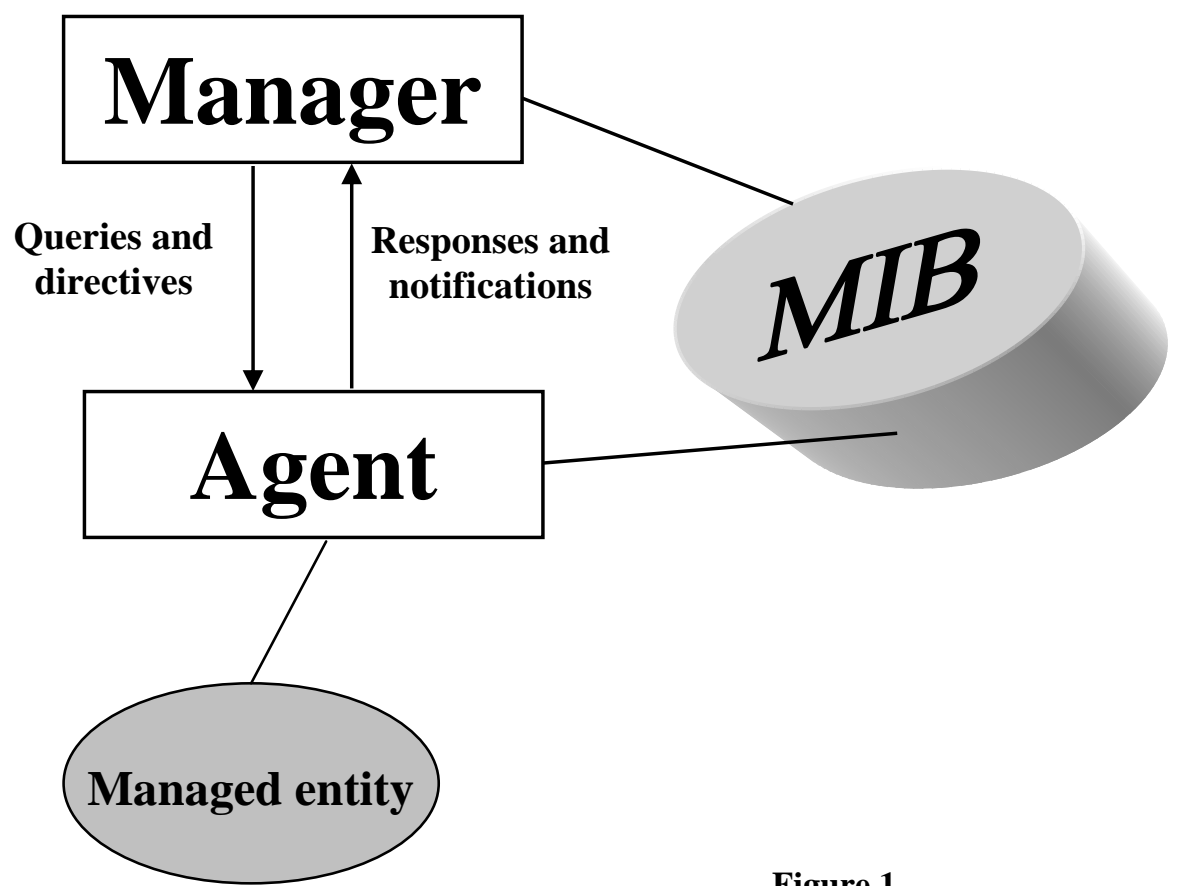

Figure 1

Usually, the manager is analogous to the client and the agent to the server. But in some cases, event reporting can be prearranged at the configuration level so that the agent reports events without explicit request from the manager. This represents a departure from the classical client-server model, because the roles played by the agent and the manager and the agent are switched. The agent initiates a reporting action, so it acts as a client. The manager reacts to the agent's action, so it behaves like a server. Swapping the roles is not part of a client-server model.

A manager is a software program that can query agents, receive responses from agents, and send directives to them. An agent is a software program (often residing on the managed entity) that responds to manager requests and performs management functions on the managed entities (communication and application software resources capable of being monitored and controlled). A management information base (MIB) is a conceptual representation of information related to a managed entity and how users can access it.

The agent acts as an interpreter of information resources contained in the MIB, providing filtering of the information and informing the manager about autonomous events that occurred. Communication between agent and manager is performed as a 
set of requests, responds, and autonomous messages as defined by specific standards. According to OSI, MIB is a collection of managed object classes defined in the special purpose notations described in the guidelines for the definition of managed objects (GDMO), ITU-T Recommendation X.722. TMN standards are much more complex and more difficult to implement than SNMP. However, they are much more powerful and efficient for large-scale networks. There is an objective need of a proliferation of proprietary interfaces at network elements. It and some other reasons have led to the adoption of Common Object Request Broker Architecture (CORBA) in network software management, because standard distributed object technologies including CORBA offer low-cost development platforms and tools. Moreover CORBA is vendor independent and is thus the logical choice for systems that must operate in a heterogeneous environment. With CORBA agents in all network elements (NEs), we can develop a purely CORBA-based network management system. However, the CORBA-based architecture reuses existing MIB specifications using gateways between CORBA-based network management applications and CMIP/SNMP-based network elements. The term agent is highly overused. On the one hand, we have systems like SNMP and CMIP agent that are nothing more than servers providing data to their clients - management applications. On the other side of the spectrum, there are expert systems with huge knowledge bases, which are also considered agents due to their intelligent behavior. Talking about an intelligent agent we have in mind a computational entity that acts on behalf of others, is autonomous, is both proactive and reactive, and exhibits a certain degree of ability to learn, cooperate, and move. A "client" delegates to an agent certain tasks that are to be achieved without, or with a minimum of, his further involvement. After receiving the task, the agent acts autonomously following certain algorithms. Using their skills, agents proactively try to attain the goal defined by the assigned task. They can acquire their skills by being told (education) or through expertise (observation). Agents react to changes in the available data by modifying their plans. They acquire and modify their knowledge in response to experience and exchange of information. They also communicate to share their knowledge and collaborate in attaining their goals. Agents may have to be mobile to achieve their goals. A mobile agent is an agent that can be moved between execution environments. The use of mobile agents addresses efficiency, reduction of network traffic, asynchronous autonomous operation, local interaction with real-time systems, support for heterogeneous environments, on-line extensibility of services and convenient development paradigms. It is a common opinion that creating distributed systems based on mobile agents is relatively easy.

The conclusion is, that we have to be ready to see in the near future a fast growing number of applications of the above described and similar technologies for solving the current problems of distance education learning software. 
Distance learning as a form of training has been recognized and is gaining speed in the military sphere. The Training and Education Enhancement Program (TEEP) outlines that distance learning of English, through the present and future electronic networks, could be an option, as mentioned earlier, for Partners to access basic or specific English Training modules. This area will be further explored as a part of TEEP Distributed Learning and Simulation.

The authors of this article have participated in the designing of software for a project for the system named Partnership for Peace Learning Management System (PfPLMS). This is a software development project that aims to provide a free or low cost solutions to Partnership for Peace Nations organizations, to evaluate the benefits of using Advanced Distributed Learning (ADL) technology to assist them in the quality, throughput, and effectiveness of their training programs. It attempts to focus in on the requirements and particulars of organizations working under the auspices of the PfP Consortium of Defense Academies and Security Studies Institutes, as the particular challenges seen in training military officers and civilian leadership is of special importance politically to the stability of PfP Nations.

The system itself can be described as a software repository that can hold, manage and facilitate the interaction of student-instructor relationships around a particular course. It combines catalogue features, coarse design features, including re-use of existing material, and automated procedures for students to interact with course material, and course instructors located elsewhere.

The project differs fundamentally from other development projects, in that a definitive statement of work, or compilation of users requirements did not exist prior to the initial stated requirements for this system. The background may be divided into two sections: emerging technical requirements to satisfy the MOU concerning Advanced Distributed Learning, and a prototype project begun to offer a single course. As part of the process of 'deconstructing', or interpreting the MOU, the primary agencies responsible for oversight of the MOU perceived the MOU to call for the design, creation, population, and long term maintenance of a centralized repository of Distance Learning Courses, to be:

1. Used by Partner organizations in their attempts to further their interoperability and integration into NATO/Western European engagement.

2. As much as possible to adhere to emerging US DoD standards for Distance Learning (SCORM), to further future interoperability amongst allies.

3. To lay the groundwork for an eventual "virtual defense academy", where courses affecting military and civilian leaders could be maintained virtually, encompassing courses, instructors, and students from various locations, positions, etc. 
As part of this effort, the Joint Planning Committee comprised to oversee the implementation of this MOU primarily concerned themselves with identifying the applicable standards, courses that could be made available, and teams to assist course providers in the conversion of these courses into an online system.

From a technological point of view this project (Version 1) can be described as a distributed in INTERNET combination of system and application software. As a database management software is used Postgress, contacted from scripts using SQL style statements, which in our opinion is appropriate for relatively small software systems. Almost all of the scripts for communication with databases and Internet browsers are written using Perl language and CGI (Common Gateway Interface) standard. In order to speed up the work of the application software, in our opinion, it would be better if Perl's DBI modules were used. The result would be, first, higher speed transactions between the databases and user's site in Internet, and second, it would provide more standard access to the databases. The last remark is important, since this is intended to be an open source project and in the future different designers from different software teams and different countries should be able to add in a more uniform way their contribution in the development of this project.

Efforts have been made to modify the proposed schema for this current cycle to be more in line with mandatory object descriptors as advocated by SCORM. Similar changes to improve the ability to exchange information could also be accommodated. It should not, however, be confused that the particular requirements for an LMS for a PfP audience may differ in its implementation than that designed for a US or Western European audience. Efforts should be made to ensure compatibility where possible, but functionality, user friendliness, or real world constraints such as communications, local equipment, language barriers, etc., should not be sacrificed to ensure full compliance. 


\section{Notes:}

1. PfP Learning Management System. ESSO Project, Working Paper, (Consortium of Defense Academies and Security Studies Institutes, IT Working Group, September 2000).

2. David J. Sidor, "TMN Standards: Satisfying Today's Needs While Preparing for Tomorrow," IEEE Communications Magazine (March 1998): 54-64.

3. J. Patrick Thompson, "Web-Based Enterprize Management Architecture," IEEE Communications Magazine (March 1998): 80-86.

4. Neal Calanni, "A New Breed of VPNs," Business Communications Review International (October 2001): 50-53.

5. James F. Kurose and Keith W. Ross, Computer Networking: A Top-Down Approach Featuring the Internet (Addison Wesley, 2001).

GRETA KEREMIDCHIEVA: MA (1985 English philology) degree from Sofia University. Specialization in Management of English Language Training, USA, Military Materials Design, UK, English Language Testing for Military Personnel. Currently, she works as Chief of English Language Training Department at the "Rakovski" Defense and Staff College.

PLAMEN YANKOV: MSc (1985 Radio Electronic Equipment of Airplanes) Air Force Academy; MSc (1991 Computer Science) Technical University Varna. Specialization in Computer Networks Management, Keesler AFB, USA; Arms Control Procedures and Information Systems, Germany. Currently, he works as a researcher in the Defence Advanced Research Institute, "Rakovski” Defense and Staff College. 